Ларченко Ю. Г., Повханич Н. Н.

J. G. Larchenko, N. N. Povkhanich

МЕТОДИЧЕСКИЕ ПОДХОДЫ К ОЦЕНКЕ КОНКУРЕНТОСПОСОБНОСТИ РОЗНИЧНЫХ ТОРГОВЫХ ПРЕДПРИЯТИЙ

\title{
METHODICAL APPROACHES TO THE ASSESSMENT OF RETAIL TRADE ENTERPRISE COMPETITIVENESS
}

Ларченко Юлия Геннадьевна - кандидат экономических наук, доцент кафедры сервиса и торгового дела Комсомольского-на-Амуре государственного технического университета (Россия, Комсомольскна-Амуре). E-mail: 1_uliya_g@mail.ru.

Ms. Julia G. Larchenko - PhD in Economics, Associate Professor, Department of service and business, Komsomolsk-on-Amur State Technical University (Russia, Komsomolsk-on-Amur). E-mail: 1_uliya_g@mail.ru.

Повханич Наталья Николаевна - студент магистратуры 1-го курса факультета экономики и менеджмента направления «Торговое дело» Комсомольского-на-Амуре государственного технического университета (Россия, Комсомольск-на-Амуре). E-mail: povkhanich_natala@mail.ru.

Ms. Natalya N. Povkhanich - Master's Degree Student of the first year major in business, economics and management faculty, Komsomolsk-on-Amur State Technical University (Russia, Komsomolsk-on-Amur). E-mail: povkhanich_natala@mail.ru.

Аннотация. В статье рассматриваются методические подходы к оценке конкурентоспособности розничного торгового предприятия. Особое внимание уделяется характеристике инструментов исследования конкурентоспособности предприятия, основанных на факторах формирования конкурентного потенциала коммерческого предприятия в сфере розничной торговли, выделяются их преимущества и недостатки.

Summary. The article considers methodological approaches to the assessment of the competitiveness of retail trade enterprises. Particular attention is paid to epy research of enterprise competitiveness, based on the business competitive potential in the retail sector. The authors highlighted their advantages and disadvantages of retail trade enterprises.

Ключевые слова: розничное торговое предприятие, конкурентоспособность, методы оценки конкурентного потенциала предприятия.

Key words: retail trade enterprise, competitiveness, assessment methods of the enterprise competitive capacity.

УДК 339.138

В условиях активного влияния факторов макросреды на российскую экономику большинство отечественных предприятий промышленности и сферы услуг столкнулись с необходимостью формирования и поддержания конкурентной позиции на внутреннем рынке деятельности. В этой связи возникает задача анализа существующих методик оценки уровня конкурентоспособности коммерческих предприятий и их адаптации к современным условиям хозяйствования, что свидетельствует об актуальности и практической значимости выбранной темы исследования.

В общем виде конкурентоспособность коммерческого предприятия - это способность хозяйствующего субъекта удовлетворять фактические и потенциальные потребности рынка по сравнению с аналогичными путями их удовлетворения, представленными на рынке.

Наиболее часто конкурентоспособность коммерческого предприятия описывают как совокупность внутренних и внешних факторов, которые формируют конкурентный потенциал предприятия в краткосрочной перспективе (см. табл. 1). 
Ларченко Ю. Г., Повханич Н. Н.

МЕТОДИЧЕСКИЕ ПОДХОДЫ К ОЦЕНКЕ КОНКУРЕНТОСПОСОБНОСТИ РОЗНИЧНЫХ ТОРГОВЫХ ПРЕДПРИЯТИЙ

Таблица 1

Методические подходы к оценке конкурентоспособности розничного торгового предприятия

\begin{tabular}{|c|c|c|}
\hline Характеристика подхода & Преимущества и недостатки подхода & Автор \\
\hline $\begin{array}{l}\text { Авторы выделяют контролируе- } \\
\text { мые и неконтролируемые факто- } \\
\text { ры, которые определяют конку- } \\
\text { рентную позицию предприятия } \\
\text { розничной торговли на рынке. К } \\
\text { контролируемым факторам от- } \\
\text { носятся: местоположение, ассор- } \\
\text { тимент, формы продажи товаров, } \\
\text { цена, продвижение, мер- } \\
\text { чендайзинг, до- и послепродаж- } \\
\text { ное обслуживание, управление } \\
\text { персоналом, финансами, инфор- } \\
\text { мацией. В состав неконтролиру- } \\
\text { емых факторов входят факторы } \\
\text { микро- и макросреды }\end{array}$ & $\begin{array}{l}\text { По мнению авторов, совмещение внутренних и } \\
\text { внешних факторов позволит выявить базовую } \\
\text { стратегию розничного торгового предприятия: } \\
\text { дифференциация товаров, снижение издержек или } \\
\text { лидерство на рынке. } \\
\text { Данный подход является актуальным и практиче- } \\
\text { ски значимым в современных условиях. Выявле- } \\
\text { ние и корректировка факторов позволит внести } \\
\text { изменения в ранее выбранную стратегию дея- } \\
\text { тельности предприятия. } \\
\text { Трудность при реализации подхода - это слож- } \\
\text { ность количественной оценки влияния факторов }\end{array}$ & $\begin{array}{l}\text { Т. Н. Па- } \\
\text { рамонова } \\
\text { и И. Н. } \\
\text { Красюк }\end{array}$ \\
\hline $\begin{array}{l}\text { Автор описывает конкуренто- } \\
\text { способность предприятия через } \\
\text { комплекс «4ПИ»: продукт, цена, } \\
\text { доведение продукта до потреби- } \\
\text { теля, продвижение продукта или } \\
\text { маркетинговые коммуникации }\end{array}$ & $\begin{array}{l}\text { По мнению автора, конкурентоспособность ком- } \\
\text { мерческого предприятия может быть оценена с } \\
\text { помощью комплекса маркетинга. } \\
\text { Данный подход является универсальным и подхо- } \\
\text { дит для оценки конкурентоспособности предпри- } \\
\text { ятий любой отраслевой принадлежности. } \\
\text { В качестве ограничения при использовании дан- } \\
\text { ного подхода следует отметить узкий набор фак- } \\
\text { торов и сложность их количественной оценки }\end{array}$ & $\begin{array}{l}\text { В. Л. Бе- } \\
\text { лоусов }\end{array}$ \\
\hline $\begin{array}{l}\text { Автор описывает конкуренто- } \\
\text { способность предприятия через } \\
\text { следующие факторы: эффектив- } \\
\text { ность его деятельности, финан- } \\
\text { совое положение, эффективность } \\
\text { организации сбыта и продвиже- } \\
\text { ния товара на рынке, конкурен- } \\
\text { тоспособность продукции }\end{array}$ & $\begin{array}{l}\text { По мнению автора, конкурентоспособность ком- } \\
\text { мерческого предприятия может быть оценена по- } \\
\text { средством конкретного набора факторов. } \\
\text { Преимуществом данного подхода является анализ } \\
\text { конкурентоспособности товара как основы кон- } \\
\text { курентного потенциала предприятия. } \\
\text { В качестве ограничения при использовании дан- } \\
\text { ного подхода следует отметить отсутствие факто- } \\
\text { ра «Персонал» в совокупности с другими функ- } \\
\text { циональными факторами и сложность их количе- } \\
\text { ственной оценки }\end{array}$ & $\begin{array}{l}\text { И. Мак- } \\
\text { симов }\end{array}$ \\
\hline $\begin{array}{l}\text { Автор описывает конкуренто- } \\
\text { способность предприятия роз- } \\
\text { ничной торговли как совокуп- } \\
\text { ность факторов: экономической } \\
\text { эффективности, культуры тор- } \\
\text { говли, имиджа предприятия и } \\
\text { уровня качества и цены товара }\end{array}$ & $\begin{array}{l}\text { По мнению авторов, конкурентоспособность } \\
\text { коммерческого предприятия в розничной торгов- } \\
\text { ле характеризует эффективность трёх видов дея- } \\
\text { тельности: торговой, финансовой и трудовой. } \\
\text { Данный подход является актуальным и практиче- } \\
\text { ски значимым в современных условиях. } \\
\text { В качестве ограничения при использовании дан- } \\
\text { ного подхода следует отметить трудоёмкость рас- } \\
\text { чёта групповых показателей эффективности дея- } \\
\text { тельности предприятия }\end{array}$ & $\begin{array}{l}\text { Ш. Маго- } \\
\text { медов, } \\
\text { И. Койча- } \\
\text { каев }\end{array}$ \\
\hline
\end{tabular}

Из табл. 1 видно, что большинство авторов используют внутренние контролируемые факторы, которые определяют и формируют конкурентную позицию коммерческого предприятия на рынке. При этом набор факторов носит ограниченный характер и не в полной мере охватывает все функциональные направления деятельности предприятия, характеризующие его отраслевую специфику. Кроме этого, возникает сложность в количественной оценке 
ряда факторов ввиду отсутствия показателя или группы показателей, с помощью которых можно оценить их влияние.

В этой связи большинство авторов используют балльную шкалу оценок для определения влияния, в первую очередь, качественных факторов внешней среды на уровень конкурентоспособности коммерческого предприятия соответствующей сферы деятельности. В этом случае оценка производится по формуле расчёта средневзвешенной величины:

$$
\mathrm{I}_{\mathrm{j}}=\sum_{\mathrm{i}=1}^{\mathrm{n}} \mathrm{b}_{\mathrm{ij}} * \mathrm{~d}_{\mathrm{ij}},
$$

где I - групповой показатель конкурентоспособности предприятия по конкретному ј-му функциональному виду деятельности; $\mathrm{b}_{\mathrm{ij}}$ - частный показатель конкурентоспособности i-го фактора по j-му виду деятельности; $\mathrm{d}_{\mathrm{ij}}$ - удельный вес $\mathrm{i}$-го фактора в ходе достижения результатов по ј-му виду деятельности; $\mathrm{n}$ - количество факторов.

В итоге интегральный показатель конкурентоспособности коммерческого предприятия рассчитывается как среднеарифметическая или среднегеометрическая величины групповых показателей конкурентоспособности предприятия. При этом частные количественные показатели конкурентоспособности предприятия определяются путём отношения их фактических значений к плановым значениям или среднеотраслевым показателям. Частные качественные показатели оцениваются экспертами с помощью заданной ими балльной шкалы.

Применительно к розничному торговому предприятию следует выделить следующие виды деятельности, для которых рассчитывается групповой показатель конкурентоспособности: торговая деятельность, трудовая деятельность и финансовая деятельность. В качестве внутренних факторов (показателей), определяющих эффективность каждого вида деятельности, выделяют следующие:

- торговая деятельность: коэффициент завершённости покупки, количество торговых услуг, издержки потребления, полнота ассортимента и др.

- трудовая деятельность: выработка продавца, время обслуживания покупателей и др.

- финансовая деятельность: цена товара, рентабельность продаж, прибыль от реализации и др.

Перечисленные выше показатели являются количественными. Однако на практике используются и качественные показатели для оценки эффективности отдельных видов деятельности.

В заключение отметим, что в данной научной работе авторы попытались обозначить основные направления анализа конкурентоспособности розничного торгового предприятия, которые будут подробно рассмотрены в следующих публикациях. Выводы, полученные авторами в настоящей работе, показали необходимость разработки экономико-математической модели интегрального показателя конкурентоспособности применительно к конкретному объекту исследования.

\section{ЛИТЕРАТУРА}

1. Белоусов, В. Л. Анализ конкурентоспособности фирмы / В. Л. Белоусов // Маркетинг в России и за рубежом. - 2010. - № 5. - С. 63-71.

2. Воронов, А. А. Моделирование конкурентоспособности продукции предприятия / А. А. Воронов // Маркетинг в России и за рубежом. - 2010. - № 4. - С. 5-10.

3. Ларченко, Ю. Г. Проблемы оценки конкурентоспособности коммерческого предприятия (на примере розничного торгового предприятия) / Ю. Г. Ларченко // Сборник научных трудов международной научной конференции. - Пенза: ПГУАС, 2009 - С. 84-88.

4. Магомедов, Ш. Метод оценки конкурентоспособности предприятия розничной торговли / Ш. Магомедов, И. Койчакаев // Маркетинг. - 2007. - № 5. - С. 92-102.

5. Парамонова, Т. Н. Конкурентоспособность предприятия розничной торговли: учеб. пособие / Т. Н. Парамонова, И. Н. Красюк. - М.: КНОРУС, 2015. - 120 с. 